\title{
Mothers' Awareness regarding Technology Addiction for Preschool Children
}

\section{Omnia Mohammed Hassan Nassar ${ }^{1}$, Hanaa Abd-El-Gawad Abd-El-Megeed ${ }^{2}$ and Wafaa Ata Mohammed ${ }^{3}$}

\author{
(1) B.Sc. Nursing, (2) Professor of Community Health Nursing, Faculty of Nursing, Benha \\ University and (3) Lecturer of Community Health Nursing, Faculty of Nursing, Benha \\ University.
}

\begin{abstract}
Background: Preschool children are increasingly surrounded by technological devices, such as tablets, smartphones, game consoles and the internet and more susceptible to technology addiction. The aim of this study: Was to assess mothers' awareness regarding technology addiction for preschool children. Research design: A descriptive design was utilized to conduct this study. Setting: This study was conducted at three nursery schools at Benha city. Sample: Convenient sample of 300 mothers accompanied their children to nursery school. Tools: Data was collected by using two tools (I): Interviewing questionnaire to assess socio demographic characteristics of the mothers, personal characteristics of the children, Data related to child use of electronic devices, children current complaints, mothers' knowledge regarding technology addiction and mothers' reported practices to prevent technology addiction. (II): Likert scale questionnaire to assess mothers' attitudes regarding technology addiction. Results: There were $71.7 \%$ of the studied mothers had university degree and more and $94.3 \%$ of them were married, $78.3 \%$ of the studied mothers had average total knowledge about technology addiction, $71 \%$ of the studied mothers had unsatisfactory total practices regarding prevention from technology addiction and negative total attitudes regarding technology addiction. Conclusion: Less than one fifth of the studied mothers had good total knowledge about technology addiction, more than one quarter of the studied mothers had a satisfactory total practices, a positive total attitudes regarding technology addiction and there was a highly statistically significant relation between mother's age and their total knowledge score. Recommendations: Health educational and training programs are recommended to increase mothers' awareness about negative effects of technological devices, technology addiction and following a healthy life style in order to prevent it.
\end{abstract}

Keywords: Preschool children, Technological devices, Smartphones, Technology addiction and mothers' awareness.

\section{Introduction}

Nowadays preschool children live in a cyber-world based on digital connectivity. Preschool children are increasingly surrounded by technologies, such as tablets, smartphones, game consoles, TVs and the Internet. Modern touchscreens designs allow very young children to start interaction with the digital world at an earlier age. Preschool children are using Digital Technology (DT) devices anytime and anywhere, especially with the invention of smart phones and the replacement of desktop computers with digital tablets (Konca \& Koksalan, 2017).

Addiction is inability to stop doing or using something. It is characterized by lack of control in the consumption of a product or in certain behaviors. Addiction causes an excessive consumption or a limitless behavior to continue despite its adverse effects. After a 
period of time, the adverse effects become a health risk both physically and psychologically. Addiction may involve the use of substances such as drugs, alcohol or behaviors such as gambling. Technology addiction defined as a non-chemical (behavioral), passive (e.g. TV) or active (e.g. computers) human-machine interaction that induces or reinforces the features of addictive tendencies (Yucelyigit \& Aral, 2018).

Negative impact of technology addiction among preschool age children may be physical, psychological, and social, and these effects depend on the type of device, the type of use, the amount and extent of use, and the characteristics of the child. Physically, preschool children with technology addiction tend to be less physically active, increasing the risks of obesity, vision problems, sleep problems and musculoskeletal problems. Psychologically, technology addiction increases preschool children's risk of developing addictive disorders, depression, anxiety, aggressive and violent behavior, and leads children to experience difficulty in distinguishing fantasy from reality. Socially, technology addiction is associated with decreased family time and communication, increased social isolation, and hindered development of preschoolers' interpersonal skills (Hosokawa \& Katsura, 2018).

Mothers must have awareness about the total technology usage time during the day (e.g., watching television and playing games on computers, tablets, and mobile phones) should be limited to 1 hour. Mothers must be aware that children aged 2 years or younger not be allowed to face the screen. Mothers should make sure that television and technological equipment connected to the internet should be kept away from the children's bedroom. If one's children are allowed to use technological devices, the use of these devices must be subject to certain rules. Mothers must enforce that a mealtime and bedtime free from technological devices including smart phones. Mothers should be establish reasonable and firm rules for smart phones, television, computer games, internet, and social media use and these rules should not be compromised (Mustafaoglu et al., 2018).

Community health nurse must increase mothers' awareness about the importance of limiting daily screen use including TV, mobile, DVD and computer, co-viewing with children and help in understanding what the child seeing. Also give health education to the mothers about the importance of monitor children's media content and what applications are used or downloaded, test applications before the child uses them, play together, ask the child what think about the applications, keep bedrooms, mealtimes, and parent-child playtimes free form screen use for both children and parents. Community health nurse give health education to the mothers about the importance of family time and suggest that the parents can set a "do not disturb" option on the phones during these times (Drouin et al., 2020).

\section{Significance of the study}

Digital technology is a ubiquitous part of children daily lives. Technology activities along with the use of mobile devices, computers, gaming platforms and televisions increase screen use and saturate the culture among children for technology addiction (Cohen et al., 2019). A study was performed at Alexandria University about technology addiction for preschool children and the result was reported as the following: All children used mobiles and T.V while computer was used by less than half of children. The majority of children exceeded the allowed 
daily hours of using technological devices. Two thirds of mothers $67 \%$ were not aware of using mobile or tablet among the children and $33 \%$ of mothers were partially aware of mobile or tablet use. Furthermore, $87 \%$ of mothers were not aware of using computer while, only $13 \%$ of mothers were partially aware of computer use. More than half of mothers $58 \%$ were not aware of using TV compared to $42 \%$ who were partially aware (Waziry, 2019).

\section{Aim of the study}

The aim of the study was to assess mothers' awareness regarding technology addiction for preschool children.

\section{Research Questions}

- What are mothers' knowledge regarding technology addiction for preschool children?

- What are mothers' attitudes regarding technology addiction for preschool children? -What are mothers' reported practices to prevent technology addiction for preschool children?

- Is there a relation between Mothers' socio demographic characteristics and their Knowledge regarding technology addiction for preschool children?

\section{Subject and methods}

\section{Research design:}

Descriptive design was utilized to conduct this study.

\section{Setting:}

The study was conducted in $25 \%$ of all nursery schools in Benha City. Which included (3) nursery schools from 15 nursery schools. By using simple random sample three nursery schools selected which namely Revolution nursery school, Omar bin AbdulAziz nursery school and Amr Ibn-El-Aas nursery school.

\section{Sampling:}

A convenient sample was included 300 mothers accompanied their preschool children to nursery school in Benha City throughout six months from the beginning of the study.

Tools for data collection: Two tools were used for data collection.

Tool I: An interviewing questionnaire: It was consisted of four parts:

First part: Included the following:

A- Socio-demographic characteristics of the studied mothers which consisted of six items as (age, level of education, occupation, working hours, marital status, place of residence, living and number of children).

B- Personal characteristics of the studied children which consisted of three items as (age, sex, birth order).

C- Data related to child use of electronic devices which consisted of four items as (child age when started to use electronic devices, type of electronic device used by the child, duration for using electronic devices by child daily and causes that make the child to exceed the accepted duration).

Second part: Included questionnaire to assess children' current complaints as a result of technology addiction as reported by their mothers.

Third part: Included questionnaire to assess mothers' knowledge regarding technology addiction for preschool children.

Knowledge scoring system: It was calculated as follows (2) score for correct and complete answer, while (1) score for correct and incomplete answer and (0) score for incorrect and incomplete answer. These scores of the items were summed-up and the total divided by the number of the items, giving a mean score for the part. These scores were 
converted into a present score. Mother's Total knowledge score was classified as the following:

Total scores of knowledge $=20$ points

- Good when the total score was $75 \%$ to $100 \%$ (> 15 points).

- Average when the total score was 50 to less than $75 \%$ (10-15 points).

- Poor when the total score was less than $50 \%$ ( $<10$ points).

Fourth part: Included questionnaire to assess mothers' reported practice to prevent technology addiction for preschool children and was consisted of 4 parts:-

A- Mothers' reported practices regarding child use of technology.

B- Mothers' reported practices regarding child's daily hours of technology use.

C- Mothers' reported practices regarding behavior to reduce technology addiction for preschool children.

D- Mothers' reported practices about following healthy life style for their preschool children

Practice scoring system: It was calculated as follows (1) score for done and (zero) score for not done. These scores of the items were summed-up and the total divided by the number of the items, giving a mean score for the part. These scores were converted into a present score. As well as mother's total reported practices score was classified as the following:

Total scores of practices $=29$ points

- Satisfactory when the total score was $\geq 80 \%$ ( $\geq 24$ points).

- Unsatisfactory when the total score was $\leq 80 \%$ ( $\leq 24$ points).
Tool II: Likert scale to assess mothers' attitude toward technology addiction for preschool children adopted from (Fidan \& Kesici, 2018) and was modified by the investigator.

Attitude scoring system: Each step has 3 levels of answers: Agree, uncertain and disagree. These were scored respectively 2, 1 and 0 . The scores of the items were summedup and the total divided by the number of the items, giving a mean score. These scores were converted into a percent score and means and standard deviations were computed. Mother's total attitudes score was classified as the following:

Total scores of attitudes $=26$ points

- Positive when the total score was $\geq$ $80 \%$ ( $\geq 21$ points).

- Negative when the total score was $\leq 80 \%$ ( $\leq 21$ points).

\section{Ethical consideration:}

A formal consent was obtained from each mother and the aim and nature of the study was explained for each mother. Each mother had the right to withdraw at any time. Mother's verbal agreement to participate was obtained. Confidentiality of their information was assured to all mothers.

\section{Validity of tools:}

It was checked and revised by panel of five experts from Community Health Nursing Department, Faculty of Nursing at Benha University who reviewed the tool for clarity, relevance, comprehensiveness, understanding and applicability and the modifications were done accordingly based on their responses.

\section{Reliability test:}

Reliability of tools was applied for testing the internal consistency of the tools by Cronbach's Alpha test and resulted. 
Reliability for knowledge was 0.76 , for practice was 0.71 and for attitude was 0.85 .

\section{Pilot study:}

A pilot study was carried out before starting data collection on $10 \%$ (30 mothers and their preschool children) from the total sample, were excluded from the total number of study sample. The aim of pilot study was to test the applicability, practicability and clarity of the tools and estimate the time for tool data collection. According to the results of the data analysis, items corrections, modification, omissions and were done accordingly. So sample excluded.

\section{Field Work:}

A review of recent, current, national and international literature in various aspects of the problem and to prepare the tools of data collection. Field work was performed in the following sequence: The investigator introduced herself to each mother. The investigator explained the aim of the study to each mother to gain their support and cooperation. The average time needed for each sheet was around 30-45 minutes. Preparation the tools used for data collection take two months from beginning of March 2020 to end of May 2020. Mothers consent was obtained before starting the collection of data. Data were collected from the study sample was taken period from beginning of October 2020 until the end of November 2020. The investigator visited the selected nursery schools from 7 am to 9 am and from 1 $\mathrm{pm}$ to $3 \mathrm{pm}$, three days/week (Saturday, Monday and Wednesday) to collect mother's data.

\section{Statistical analysis:}

All data were organized, tabulated and analyzed by using the Statistical Package for Social Science (SPSS version 20), which was used frequencies and percentage for qualitative descriptive data and chi square was used for quantitative data, spearmean correlation test (r) was used for correlation analysis and degree of significant was identified.

\section{Statistical significance was considered at:}

Non-significant relation obtained at $\mathrm{P}>0.05$

Significant relation obtained at $\mathrm{P}<0.05$

High significant relation obtained at $\mathrm{P}<0.001$

Results:

- Table (1): Reveals that $35 \%$ of the studied mothers aged from 25 to less than 35 years old with mean and standard deviation $29.59 \pm$ 5.7. Besides, $71.7 \%$ of them had university degree and more, $94.3 \%$ of them were married, while $59.7 \%$ of them were housewife and $88.4 \%$ of the employed mothers were working from $6-8$ hours, $44.7 \%$ of them had two children. Regarding residence $60.3 \%$ of studied mothers were from urban areas and $56.3 \%$ of them were independent in their living.

- Table (2): Donates that $41.3 \%$ of the studied mothers specified that their children aged 5 years old with mean and standard deviation $4.12 \pm 0.82$ years old, while $64.7 \%$ of them specified that their children were female. Regarding birth order, $59.0 \%$ of the studied mothers specified that their children were 2 nd order.

- Table (3): Represents that 40.3\%, 48.7\%, $41.3 \%$ and $69.0 \%$ of the studied mother's specified inability of their children to wake up early as physiological complaint, inability of their children to make face to face communication with others as social complaint. Concerning psychological complaint, their children suffered from anxiety and tension when not using electronic devices for long periods as psychological complaint and suffered from decrease 


\section{Mothers' Awareness regarding Technology Addiction for Preschool Children}

attention, concentration in kindergarten stage as attention and concentration complaint.

- Figure (1): Illustrates that $78.3 \%$ of the studied mother's had average total knowledge score regarding technology addiction for preschool children, while $17.0 \%$ of them had good total knowledge score and $4.7 \%$ of them had poor total knowledge score regarding technology addiction for preschool children.

- Figure (2): Demonstrate that $71.0 \%$ of the studied mothers had unsatisfactory total reported practices score regarding technology addiction and $29.0 \%$ of them had a satisfactory total reported practices score

Table (1): Frequency distribution of the studied mothers regarding their socio demographic characteristics $(\mathbf{n}=\mathbf{3 0 0})$

\begin{tabular}{|c|c|c|}
\hline Socio demographic characteristics & $\overline{\mathbf{N}}$ & $\%$ \\
\hline \multicolumn{3}{|l|}{ 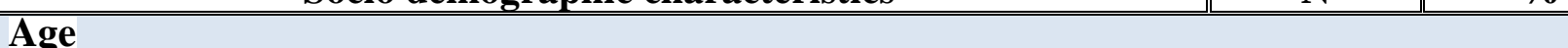 } \\
\hline$<20$ & 9 & 3.0 \\
\hline $20-$ & 56 & 18.7 \\
\hline $25-$ & 105 & 35.0 \\
\hline $30-$ & 88 & 29.3 \\
\hline $35+$ & 42 & 14.0 \\
\hline \multicolumn{3}{|c|}{ Mean \pm SD 29.59 \pm 5.7} \\
\hline \multicolumn{3}{|l|}{ Educational level } \\
\hline Secondary education & $\overline{85}$ & $\overline{28.3}$ \\
\hline University and more & 215 & 71.7 \\
\hline \multicolumn{3}{|l|}{ Marital status } \\
\hline Married & 283 & 94.3 \\
\hline Divorced & 9 & 3.0 \\
\hline Widow & $\overline{88}$ & 2.7 \\
\hline \multicolumn{3}{|l|}{ Occupation } \\
\hline Housewife & 179 & 59.7 \\
\hline Employed & $\overline{121}$ & 40.3 \\
\hline \multicolumn{3}{|l|}{ Working hours $(\mathrm{n}=121)$} \\
\hline $6-8$ hours & 107 & 88.4 \\
\hline$>8$ hours & 14 & 11.6 \\
\hline \multicolumn{3}{|l|}{ Number of children } \\
\hline One & $\overline{46}$ & 15.3 \\
\hline Two & 134 & 44.7 \\
\hline Three & 106 & 35.3 \\
\hline Four and more & 14 & 4.7 \\
\hline \multicolumn{3}{|l|}{ Place of residence } \\
\hline Urban & $\overline{181}$ & 60.3 \\
\hline Rural & 119 & 39.7 \\
\hline \multicolumn{3}{|l|}{$\overline{\text { Living }}$} \\
\hline Independent & 169 & 56.3 \\
\hline Shared & 131 & 43.7 \\
\hline
\end{tabular}

regarding technology addiction for preschool children.

- Figure (3): Revealed that $71.0 \%$ of the studied mothers had a negative total attitude score and $29.0 \%$ of them had a positive total attitude score regarding technology addiction for preschool children.

- Table (20): Reveals that there was a positive correlation between total knowledge score total practices score and total attitudes score of the studied mothers. 
Table (2): Frequency distribution of the studied mothers regarding their children' personal characteristics $(\mathbf{n}=\mathbf{3 0 0})$

\begin{tabular}{|c|c|c|}
\hline Child personal characteristics & $\overline{\mathbf{N}}$ & $\%$ \\
\hline \multicolumn{3}{|l|}{ Child age } \\
\hline $3-$ & 86 & 28.7 \\
\hline $4-$ & 90 & $\overline{30.0}$ \\
\hline $5-$ & $\overline{124}$ & 41.3 \\
\hline \multicolumn{3}{|c|}{ Mean \pm SD $4.12 \pm 0.82$} \\
\hline \multicolumn{3}{|l|}{ Sex } \\
\hline Male & 106 & 35.3 \\
\hline Female & 194 & 64.7 \\
\hline \multicolumn{3}{|l|}{ Birth order } \\
\hline $1 \mathrm{st}$ & 95 & 31.7 \\
\hline 2nd & 177 & $\overline{59.0}$ \\
\hline 3rd and more & 28 & 9.3 \\
\hline
\end{tabular}

Table (3): Frequency distribution of the studied children regarding their current complaint as a result of technology addiction as reported by their mothers $(n=300)$

\begin{tabular}{|l|c|c|}
\hline Child's current complaint as a result of technology addiction & N & \multicolumn{1}{|c|}{ \% } \\
\hline *Physiological complaint & 31 & 10.3 \\
\hline Headache & 62 & 20.7 \\
\hline Blurred vision & 30 & 10.0 \\
\hline Eye dryness & 81 & 27.0 \\
\hline Eye redness & 74 & 24.7 \\
\hline Inability to focus on small things & 46 & 15.3 \\
\hline Lack of sleep periods & 121 & 40.3 \\
\hline Inability to wake up early & 99 & 33.0 \\
\hline Nightmares & 16 & 5.3 \\
\hline Muscle spasm & 82 & 27.3 \\
\hline Decrease or increase food intake & 12 & 4.0 \\
\hline Weight gain & 37 & 12.3 \\
\hline G.I.T problems & & \\
\hline *Social complaint & 146 & 48.7 \\
\hline Inability to make face to face communication with others & 54 & 18.0 \\
\hline Inability to make new friendships & 69 & 23.0 \\
\hline Inability to play or work in a group & 114 & 38.0 \\
\hline Feeling of loneliness & 31 & 10.3 \\
\hline Feeling of introversion & 37 & 12.3 \\
\hline Feeling of extreme shyness & \multicolumn{2}{|c|}{} \\
\hline *Psychological complaint & 124 & 41.3 \\
\hline Feeling of anxiety and tension when not using electronic devices for long \\
periods
\end{tabular}

(*) Responses are not mutually exclusive 


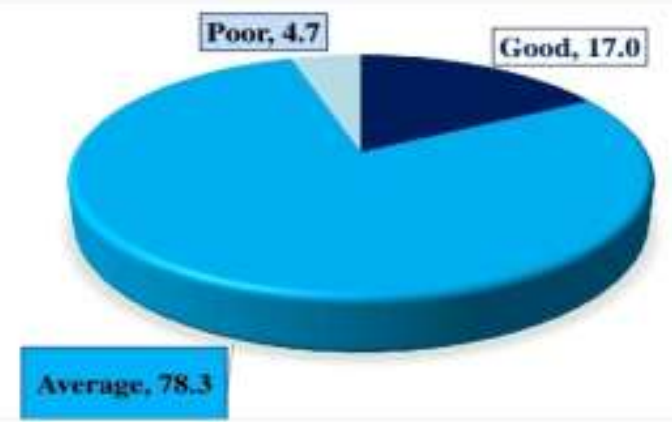

Figure (1): Percentage distribution of the studied mothers regarding their total knowledge score about technology addiction for preschool children $(n=300)$.

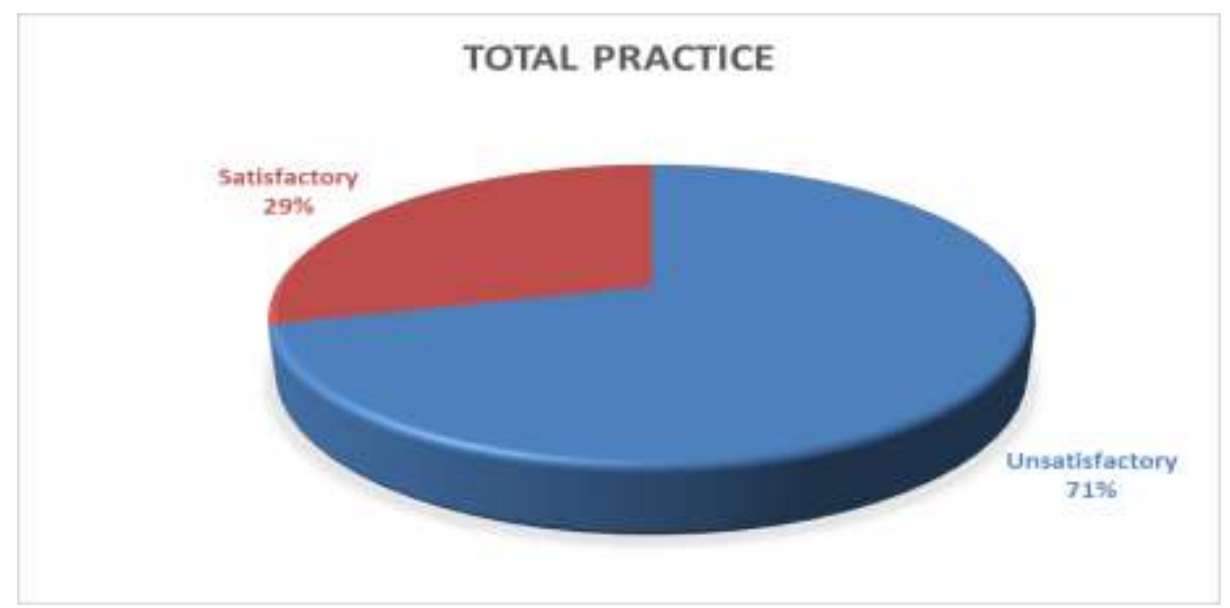

Figure (2): Percentage distribution of the studied mothers regarding their total reported practices score about prevention of technology addiction for preschool children $(n=300)$.

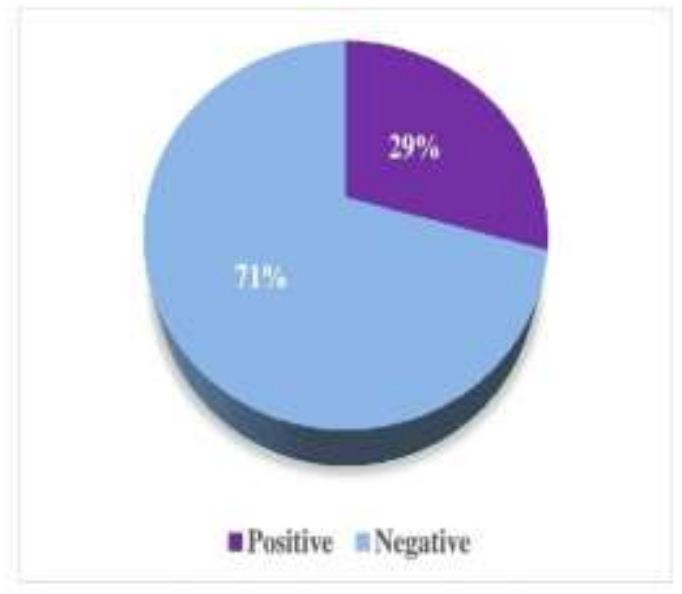

Figure (3): Percentage distribution of the studied mothers regarding their total attitude score about technology addiction for preschool children $(n=300)$. 
Table (4): Correlation between total knowledge score, total practices score and total attitudes score of the Studied mothers $(n=300)$.

\begin{tabular}{|l||c|c|}
\hline \multirow{2}{*}{\multicolumn{1}{|c||}{ Items }} & \multicolumn{2}{c|}{ Total knowledge } \\
\cline { 2 - 3 } & r. & p-value \\
\hline \hline Total practices & 0.157 & $0.007 * *$ \\
\hline Total attitudes & 0.462 & $0.000 * *$ \\
\hline
\end{tabular}

\section{Discussion:}

Technology addiction is inability to control the use of technological devices like smart phones, tablets, iPod's and TVs. Technology addiction is another form of internet addiction. The phenomenon of technology addiction in preschool children is not only related to the use of technological devices that are getting earlier but also the high duration of technological devices usage and exceeding recommended usage limits. The use of technological devices can make preschool children dependent because it have a pleasant effect and make preschool children avoid conflict. Technology addiction has many negative impacts on preschool children, which can make preschool children become less physical activity and increase the risk of obesity, increase vision problems, reduced sleep duration, low pro-social behavior, besides technology addiction is also an indicator of social isolation (Rahmawati \& Latifah, 2019).

Regarding socio-demographic characteristics of the studied mothers, the present study revealed that more than one third of the studied mothers aged between 25 to less than 35 years old with mean and standard deviation $29.59 \pm 5.7$. According to educational level, less than three quarters of the studied mothers had university degree and more. The majority of them were married. As for occupation of studied mothers, more than half of them were housewives and more than four fifth of studied mothers who worked were working from 6-8 hours. Regarding number of children, less than half of studied mothers had two children. Regarding residence less than two third of studied mothers were from urban areas and more than half of them were independent in their living.

Regarding personal characteristics of the children, the present study revealed that more than one third of the studied mothers specified that their children aged $5<6$ years old with mean and standard deviation $4.12 \pm$ 0.82 years old, while less than two thirds of studied mothers specified that their children were female and less than two thirds of them were 2 nd order.

Regarding to child's physiological complaints as a result of technology addiction, the present study revealed that less than half of the studied mothers specified inability of their children to wake up early (table 3). This finding agreed with Sundus (2018), who studied "The Impact of using Gadgets on Children at Lahore Garrison University in Pakistan" and who revealed that less than half $(42 \%)$ of the studied mothers specified that their children suffered from sleep problems as inability to wake up early. This might be due to electronic devices used at bedtimes and for late periods.

Regarding to child's social complaints as a result of technology addiction, the present study revealed that less than half of 
studied mothers specified inability of their children to make face to face communication with others,. This finding agreed with Ciboci \& Osmancevic (2019), they studied "Preschool Children and Media in Edward Bernays University College in USA" and they showed that less than half $(46.3 \%)$ of preschool children's inability to make social interaction and face to face communication with others. This might be due to extreme attachment to electronic devices and children favors to use electronic devices over other social activities.

As for child's psychological complaints as a result of technology addiction, the present study showed that less than half of studied mothers specified that their children suffered from anxiety and tension when not using electronic devices for long periods. This finding agreed with Bickham et al., (2017), they studied "Digital Media, Anxiety, and Depression in Children at Harvard university in USA" and showed that less than half $(43 \%)$ of preschool children suffered from anxiety, tension and depression. This might be due to take electronic devices away from children periodically.

Regarding child's attention and concentration complaints as a result of technology addiction, the present study revealed that less than three quarters of studied mothers specified that their children suffered from decrease attention and concentration in kindergarten stage. This study disagreed with Farchakh et al., (2020), they studied "Video Gaming Addiction and its Association with Memory, Attention and Learning Skills in Lebanese Children" and they showed that less than half $(44.7 \%)$ of studied mothers specified that their children suffered from inability to think logically. This might be due to distraction related to extra use of electronic devices.
Regarding to the studied mothers' total knowledge score about technology addiction for preschool children, the current study cleared that more than three quarters of the studied mothers had average total knowledge score about technology addiction for preschool children, while less than one fifth of them had good total knowledge score about technology addiction for preschool children. These findings disagreed with Caliskan et al., (2018), they studied "Effects of Triple P on Digital Technological Device Use in Preschool Children at Nevsehir University in Turkey" and they reported that more than half $(57 \%)$ of their participants had average total knowledge score, while less than one third $(31.7 \%)$ of them had good total knowledge score about technology addiction for preschool children. This might be due to decrease media campaigns about technology addiction among preschool children.

Regarding mothers total practices score about technology addiction for preschool children, the present study showed that less than three quarters of the studied mothers had unsatisfactory total reported practices score regarding technology addiction and more than one quarter of them had a satisfactory total reported practices score. These findings disagreed with Ohmann et al., (2018), they studied "Internet Gaming Disorder in Children and Adolescents: A systematic Review at Medical University of Vienna, in Austria" and they founded that less than half $(45.3 \%)$ of the studied mothers had unsatisfactory total reported practice score regarding technology addiction and more than one third $(38.3 \%)$ of them had satisfactory level. This might be due to lack of mothers' experience about how to prevent technology addiction for preschool children. 
According to mothers' total attitudes score about technology addiction for preschool children, the present study revealed that less than three quarters of studied mothers had a negative total attitudes score regarding technology addiction and more than one quarter of them had a positive total attitudes score regarding technology addiction (figure 3). These findings contrast with Shin \& Li (2017), they studied "Parental Mediation of Children's Digital Technology Use at Nanyang Technological University in Singapore" and they revealed that more than half $(53,7 \%)$ of the studied mothers had a negative total attitudes score regarding technology addiction and less than half (41\%)of them had a positive total attitudes score regarding technology addiction. This might be due to lack of mothers' control on their children's electronic devices use.

Regarding correlation between Total knowledge, Practices and Attitudes Scores among Studied mothers, the present study revealed that there was a positive correlation between mother's total knowledge score, total practices score and total attitudes score of the studied mothers. These findings agreed with Tewenge (2019), who studied "More Time on Technology, Less Happiness? Associations between Digital-Media Use and Psychological Well-being at San Diego State University in USA" they showed that there was a positive correlation between total knowledge score, total practices score and total attitudes score of their study participants.

\section{Conclusion:}

Less than one fifth of the studied mothers had good total knowledge about technology addiction, more than one quarter of the studied mothers had a satisfactory total practices, a positive total attitudes regarding technology addiction and there was a highly statistically significant relation between mother's age and their total knowledge score.

\section{Recommendations:}

1- Health educational and training programs are recommended to increase mothers' awareness about negative effects of technological devices, technology addiction and following a healthy life style in order to prevent it.

2- Booklets with illustrated pictures about technology addiction and it's prevention among preschool children should be available at nursery schools.

3- Further studies about technology addiction need to perform on large samples of children in order to highlight technology addiction among preschool children.

\section{References}

Bickham, D., Cantor, J., \& Hoge, E. (2017). Digital media, anxiety, and depression in children. Pediatrics, 140(Supplement 2): P7680 .

Caliskan, Z. Dinsever, C., Eygin, D., Ozyurt, G. (2018). Effects of triple $\mathrm{P}$ on digital technological device use in preschool children. Journal of Child and Family Study, 27: P280-289. Available online on: https://doi.org/10.1007/s10826-017-0882-6.

Ciboci, L., \& Osmancevic, L. (2019). Preschool children and media. The international encyclopedia of media literacy, P1-4.

Cohen, S., Doswell, w., Kaufmann, P., Liu, J., Riesch, s., \& Vesseu, J. (2019). Preventing adverse health outcomes among children and adolescents by addressing screen media practices concomitant to sleep disturbance, Nursing outlook , 67 (4): P 492496. 
Drouin, M., McDaniel, B. \&Newsham, G. (2020): Problematic phone use, depression, and technology interference among mothers. Psychology of Popular Media, 9(2): $\quad$ P117-124. https://doi.org/10.1037/ppm0000220.

Farchakh, Y., Haddad, C., Hallit, S., Obeid, S., Sacre, H., \&Salameh, P. (2020). Video gaming addiction and its association with memory, attention and learning skills in Lebanese children. Child and Adolescent Psychiatry and Mental Health, 14 (1): P1-11.

Fidan, N. \& Kesici, A. (2018). The Development of the Digital Addiction Scale for the University Students: Reliability and Validity Study, Universal Journal of Educational Research, 6(1): P 91-98

Hosokawa, R., \& Katsura, T. (2018). Association between mobile technology use and child adjustment in early elementary school age. PloS one, 13 (12): e208844. https://doi.org/10.1371/journal.pone.0199959.

Konca, A. \& Koksalan, B. (2017). Preschool children's interaction with ICT at home. International Journal of Research in Education and Science (IJRES), 3 (2): P571581. DOI 10.21890/ijres.328086.

Mustafaoglu, R., Razak Ozdinçler, A., Yasacı, Z., \& Zirek, E. (2018). The negative effects of digital technology usage on children's development and health. Addicta: The Turkish Journal on Addictions, 5 (2): P227-247 Available online at: http://dx.doi.org/10.15805/addicta.2018.5.2.0 051.

Ohmann, S., Paulus, F., Von Gontard, A., \& Popow, C. (2018). Internet gaming disorder in children and adolescents: a systematic review, Journal Developmental
Medicine \& Child Neurology, 60 (7): P645659.

Rahmawati, M., \& Latifah, M. (2019). The Effect of mother-child interaction and maternal gadget use on child's gadget addiction in preschool children. Department of family and consumer sciences, Faculty of Human Ecology, IPB University, Indonesia, P70.

Shin, W., \& Li, B. (2017). Parental mediation of children's digital technology use in Singapore. Journal of Children and Media, 11 (1): P1-19.

Sundus, M. (2018). The Impact of using Gadgets on Children. Journal of Depression and Anxiety, 7: P296. doi:10.4172/21671044.1000296.

Twenge, J. (2019). More time on technology, less happiness? Associations between digitalmedia use and psychological well-being. Current Directions in Psychological Science, 28 (4): P372-379.

Waziry, O. (2019). Mothers' awareness of technology addiction, International Journal of Novel Research in Healthcare and Nursing, 6 (1): P786-802.

Yucelyigit, S., \& Aral, N. (2018). Technology Addiction in Children. Educational Sciences Research in the Globalizing World, st. kliment ohridski university press Chapter 7: P 66. 


\section{وعي الامهات تجاه ادمان التكنولوجيا لدي الاطفال في سن ما قبل المدرسه \\ امنيه حمحل حسن-هناء عبدالجو اد عبدالمجيد-وفاء عطا محمد}

أصبح الأطفال في سن ما قبل المدرسة محاطين بشكل متز ايد بالأجزة التكنولوجية ، مثل الأجهزة اللوحية

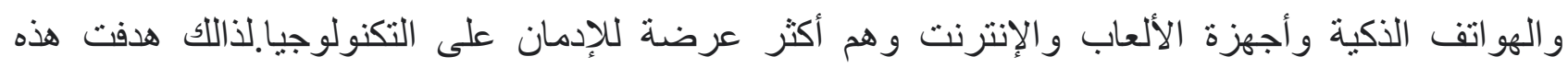

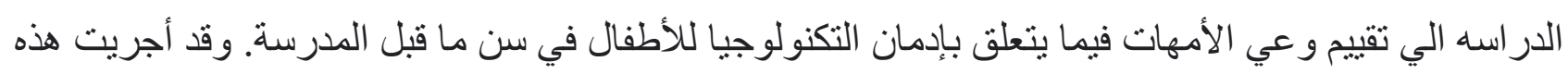

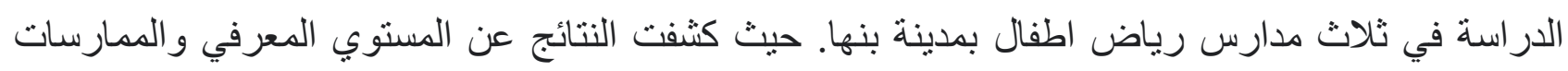

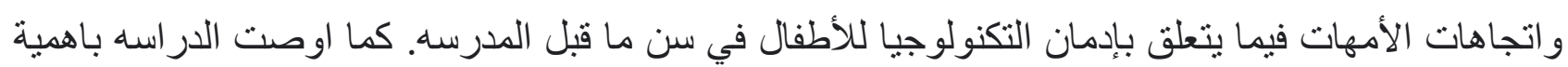

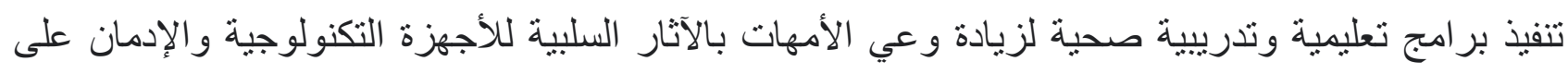
التكنولوجيا و اتباع أسلوب حياة صحي للوقاية منه. 